\title{
Lay Theories and Intergroup Relations
}

\author{
Sheri R. Levy \\ State University of New York at Stony Brook \\ Chi-yue Chiu and Ying-yi Hong \\ University of Illinois at Urbana-Champaign
}

Lay theory research on intergroup relations has rapidly grown over the past two decades. Drawing on articles in this Special Issue, we showcase the latest developments. First, we define lay theories, addressing the extent of overlap with scientific theories and differences among lay theories in terms of type of representation, level of articulation, frequency of activation and use, range of applicability, and degree of universality. Second, we describe advances in the understanding of the functions of lay theories. Third, we review the far-reaching implications of lay theories for group and intergroup processes. Fourth, we discuss the movement toward comparing and contrasting related lay theories. Taken together, these articles suggest the study of lay theories provides a fuller understanding of intergroup relations.

KEYWORDS group processes, intergroup processes, intergroup relations, lay theories, lay theory research

PEOPLE's perceptions are filtered through and guided by their lay theories (e.g. Fletcher, 1995; Furnham, 1988; Gelman, 2003; Wegener \& Petty, 1998; Yzerbyt, Judd, \& Corneille, 2004). Work on lay theories is an abundant area of research as indicated by a recent PsycINFO search (June 27, 2005), showing a total of 882 records indexed with the following terms: 'lay theory', 'implicit theory', 'naïve theory', or 'folk theory'. Examining the abstracts of these records, we discerned a clear increasing trend over the last two decades in the number of papers concerning lay theories and intergroup relations, broadly defined to include work on stereotyping, prejudice, discrimination and group differences as a function of age, gender, race, and culture. A review of the abstracts also revealed the study of a diverse set of lay theories such as essentialism (e.g. theory about the core qualities of a group, Haslam, Rothschild, \& Ernst, 2000, 2002; Yzerbyt, Rocher, \& Schadron, 1997), entitativity beliefs (e.g. theory about what defines a group, Lickel, Hamilton, \& Sherman, 2001; Yzerbyt, Rogier, \& Fiske, 1998), incremental versus entity theories (theories about the malleability vs. fixedness of human attributes, e.g. Hong, Chiu, Yeung, \& Tong, 1999; Levy, Stroessner, \& Dweck, 1998), Protestant work ethic (theory that hard work leads to

\footnotetext{
Author's note

Address correspondence to: Sheri R. Levy, Department of Psychology, SUNY Stony Brook, Stony Brook, NY 11794-2500, USA

[email: sheri.levy@sunysb.edu]
} 
success, e.g. Crandall, 1994; Levy, Freitas, \& Salovey, 2002), and belief in a just world (theory that people deserve what they get and get what they deserve, e.g. Lerner, 1970; Montada, 1998). This work has shown that lay theories can reliably relate to people's stereotyping, prejudice, and discrimination toward members of groups including racial and ethnic groups (e.g. Katz \& Hass, 1988; Levy et al., 1998), national groups (e.g. Hong et al., 1999; Kashima et al., 2005), gay men and lesbians (e.g. Biernat, Vescio, \& Theno, 1996; Haslam et al., 2002), women (e.g. Crandall \& Martinez, 1996; Mahalingam \& Rodriguez, 2003), homeless persons (e.g. Levy et al., 2002; Somerman, 1993), overweight persons (e.g. Biernat et al., 1996; Crandall, 1994), as well as novel groups (e.g. Ip, Chiu, \& Wan, in press; Levy et al., 1998; Yzerbyt et al., 1998).

The goal of this Special Issue is to capture the latest wave of research on the role of lay theories in group and intergroup processes. In this introduction, we describe the lay theory approach with special attention to how research included in this Special Issue is refining the approach. First, we describe conceptual parameters of lay theories. Second, we describe advances in understanding the epistemic, psychological, and social functions of lay theories. Third, we spell out the far-reaching implications of lay theories for group processes and intergroup relations. Fourth, we discuss the movement toward comparing and contrasting related lay theories.

\section{Conceptual parameters of lay theories}

\section{Extent of overlap with scientific theories}

In early theorizing, a scientist mindset was attributed to lay theorists (e.g. Heider, 1958; Kelly, 1955; Piaget \& Garcia, 1983/1989). The human-as-scientist metaphor highlights some similarities between lay theories and formal theories in science. First, lay theories, similar to scientific theories, reduce epistemic uncertainty by providing understanding, prediction, and control (e.g. Heider, 1958; Hong, Levy, \& Chiu, 2001; Kelly, 1955; Plaks, Grant, \& Dweck, 2005; Yzerbyt et al., 1997). Second, 'like scientific theories, lay theories seem to represent a structured and coherent system of beliefs, rules, and concepts; lay theories are not simply shopping lists of causal propositions or concepts' (Fletcher, 1995, p. 81; also see Furnham, 1988; Hong et al., 2001; Wegener \& Petty, 1998). For example, in this issue, Jayaratne et al. (2006, p. 79) define a genetic lay theory as 'an organized belief structure reflecting the view that genes influence, to some degree, human traits'.

Scientific theories and lay theories also share some content and likely influence each other. Formal theories can inspire and give validity to lay theories (e.g. Jayaratne et al., 2006), and lay theories can inspire the construction of formal theories whether explicitly, unconsciously, or automatically (e.g. Heider, 1958; Fletcher, 1995; Furnham, 1988). As pointed out by Fletcher (1995, p. 26), the methodologies used by psychologists such as asking participants to provide free-responses or ratings that later comprise a measure of the scientist's theory essentially 'build folk theory into the overarching theory, a fact that is typically mentioned in passing or apparently going unnoticed' (also see Heider, 1958). Compelling parallels between lay and scientific theories have been suggested (see Fletcher, 1995). For example, in this issue, Sommers and Norton (in press) discerned conceptual overlap between differing lay theories of White racists and the distinction drawn by psychologists between 'old-fashioned' racism and a modern, subtle form of bias. Also, in this issue, Jayaratne et al. (2006) noted parallels between genetic lay theories and scientific and public discourse on genetic explanations for individual characteristics. In addition, lay people subscribing to an incremental theory, which focuses on mediating circumstances, appear similar to social-cognitive theorists of personality whereas lay people subscribing to an entity theory, which focuses on fixedness of traits, appear similar to trait theorists of personality (e.g. Chiu, Hong, \& Dweck, 1997).

Although lay theories and formal theories resemble each other in structure, function, and content, lay theories are not simply lay people's 
scientific theories. Whereas formal theories are important epistemic tools scientists use to approximate the truth, lay theories are phenomenological constructions used for everyday sense making. Accordingly, lay theories need not be true or even easily testable; their role in providing a perception of truth seems most important (e.g. see Crandall, 2000; Hong et al., 2001; Yzerbyt et al., 1997). This is not to say that lay theorists are not interested in accuracy; they just seem less likely to put their theories to as rigorous a test as scientists do (e.g. Plaks et al., 2005). A lay person 'often seeks for verification rather than falsification' (Furnham, 1988, p. 4) and relies on anecdotal evidence.

Lay theories and scientific theories diverge in other key ways, as elaborated in subsequent sections. Lay theories are generally less explicit and less rigorously formulated than scientific theories. Lay theories appear to be more blatantly self-serving than scientific theories; they serve social and psychological functions such as protecting the self from perceived threats, fostering social relationships, and supporting values. Using lay theories to best suit their needs in a particular situation or over time, lay people may subscribe to opposing lay theories and use a single lay theory in opposite ways.

It is also increasingly clear that lay theories differ from one another and do not represent a monolithic category. As discussed next, lay theories can differ in terms of type of representation, level of articulation, frequency of activation and use, range of applicability, and degree of universality.

\section{Type of representation}

There is a growing consensus that lay theories are knowledge structures (Dweck, Chiu, \& Hong, 1995a, 1995b). However, there are differences in opinions on what kind of knowledge structures lay theories are. The dialogue seems to be centered on the gray area between whether lay theorists are seeking and using what they believe to be accurate theories of their social world (ontological assumptions) or whether they are seeking and using lay theories that reflect their observations and experiences (narrative representations). These two perspectives on lay theories can be differentiated, as discussed next, but, to foreshadow, are intertwined in that lay people may believe that lay theories based on close observation and experience do reflect an accurate reality.

Some theorists maintain that lay theories are lay ontological assumptions (e.g. Haslam, Rothschild, \& Ernst, 2004; Kashima et al., 2005). As such, a lay theory is what lay people believe to be true about certain objects, certain properties of an object, or interrelations between objects (broadly defined). For example, in this issue, Haslam, Bastian, Bain, and Kashima (2006) define essentialism as 'a naive ontology positing that categories have a deep and unobservable reality, that this reality or "essence" gives rise to the surface features of category members (i.e. "dispositionism"), that it is unchanging and unchangeable by human intervention, and that it has a "natural" basis' (p. 64).

Ontological assumptions can be further broken down into subtypes. One subtype concerns an object's specific features, such as group stereotypes, which may take the representational format of what a group is like or what prototypic traits it possesses. Examples include lay theories of White racists (Sommers \& Norton, 2006) and of entitativity (e.g. Demoulin, Leyens, \& Yzerbyt, 2006; Denson, Lickel, Curtis, Stenstrom, \& Ames, 2006). A second subtype concerns the nature of object properties, which may take the representational form of a group attribute as nonmalleable or biologically determined. Examples are essentialism or entity theories (see e.g. Demoulin et al., 2006; Denson et al., 2006; Haslam et al., 2006; Jayaratne et al., 2006) and essentialist versus social contructivist theories of race (Chao \& Hong, 2005; No \& Hong, 2005). A third subtype concerns the interrelations of objects. As examples, the genetic lay theory suggests that genes influence traits (Jayaratne et al., 2006), the Protestant work ethic suggests hard work leads to success (e.g. Levy, West, Ramirez, \& Karafantis, 2006), and a belief in a just world suggests that people deserve what 
they get and get what they deserve (e.g. Lerner, 1970; Montada, 1998). Ontological assumptions of the first and third subtypes carry specific contents, whereas ontological assumptions of the second subtype do not. Whereas ontological assumptions of the first subtype pertain to what an object (or group) is like, ontological assumptions of the third subtype pertain to how things work or should work in a particular context and thus contain both descriptive and prescriptive elements. Compared to ontological assumptions of the first subtype, ontological assumptions of the second subtype are higher-order assumptions.

Other scholars, by contrast, have treated lay theories as generalized narrative representations (Ross, 1989; Wyer, 2004). For example, Wyer (2004, p. 267) states that

The construction of narrative representations from new information obviously requires prior knowledge about the type of persons, objects, and events to which the information refers. This knowledge, which often has implications for features that are not specified in the information presented, can sometimes include episode models of specific past experiences that have features in common with the new one. However, it can also consist of generalized narrative representations that are composed of object and event concepts that the new information exemplifies ... these latter representations often function as implicit theories that individuals apply in comprehending new experiences and construing their implications.

Examples of lay (or implicit) theories that take the form of a generalized narrative representation include lay theories about how marital relationships change over time (e.g. Knee, Patrick, \& Lonsbary, 2003), how intelligence and personality develop (e.g. Chiu, Hong, \& Dweck, 1994), and how people change with age (e.g. Ross, 1989). Entity and incremental theories of human attributes, which fit in with the second subtype of ontological assumptions described above, also qualify as generalized narrative representations, according to Wyer (2004).

As mentioned, a lay theory (entity theory of personality) can be both an ontological assumption and a narrative representation. Treating an entity theory as an ontological assumption draws attention to the resemblance between this theory and other lay theories (e.g. essentialism) in terms of their similar consequences on group perceptions (see Bastian \& Haslam, in press; Haslam et al., 2006). At the same time, treating an entity theory as a narrative representation draws attention to the conceptually driven cognitive processes that mediate the lay theory's construction and maintenance. Such processes include evaluative encoding of social information (Hong, Chiu, Dweck, \& Sacks, 1997), bases of social categorization (Tong \& Chiu, 2002), and processing of trait-consistent and inconsistent information (Plaks, Stroessner, Dweck, \& Sherman, 2000).

This proposed taxonomy is not meant to be exhaustive but rather illustrative of a theoretical language to compare and contrast different types of lay theories. It seems beneficial to consider and test whether ontological assumptions are generalized narrative representations and vice versa. For instance, this can help us understand whether people believe their lay theories to be universally true and thus apply them in all situations and over time or whether people believe their lay theories to have a more limited range of application, reflecting their specific experiences or a specific situation. Also, greater clarification of the representational nature of lay theories is advantageous as more lay theories are identified and as the interrelation among lay theories is increasingly outlined.

\section{Level of articulation}

Lay theories have been characterized as 'naive' (Heider, 1958), suggesting they are not rigorously formulated. Also, lay theorists are thought to not necessarily be aware of the tremendous impact their lay theories have on their social understanding and behavior (e.g. see Furnham, 1988; Hong et al., 2001; Wegener \& Petty, 1998).

Some lay theories, however, are more explicit than others. For example, in this issue, Jayaratne et al. (2006) suggest that 'unlike most other lay theories discussed in the psychological literature, genetic lay theories occur within an ongoing, scientific and public dialogue that generates enormous controversy. In this way, 
they are more explicit than other lay theories' (p. 79). Also, some lay theories captured by everyday proverbs such as 'El perico donde quiera es verde' (A parrot is green wherever it goes; entity theory, see Levy, Plaks, Chiu, Hong, $\&$ Dweck, 2001), 'What goes around comes around' (belief in a just world, Lerner, 1970; Montada, 1998) or 'The early bird gets the worm' (the Protestant work ethic, see Levy et al., 2006) are likely fairly frequently voiced. Nonetheless, research has not tested differences between lay theories in level of articulation.

Despite potential differences in level of explicitness, lay theories generally are assessed via self-report (see Dweck, 1999; Furnham, 1988). As illustrated by each of the articles in this Special Issue, lay people tend to be provided with simple, straightforward statements reflecting those lay theories and appear able to reflect and endorse their views accordingly. As a shortcoming with self-report measures, there is the concern that people report more than they know (Nisbett \& Wilson, 1977). However, studies in which people's lay theories are temporarily induced provide similar findings as when the lay theories are simply measured by self-report (e.g. Chiu, Hong et al., 1997; Haslam \& Ernst, 2002; Levy et al., 1998, 2006; Plaks et al., 2000).

\section{Frequency of activation and use}

Lay theories are knowledge structures. Therefore, their activation and application follow basic principles of knowledge activation (e.g. Higgins, 1996; Hong et al., 2001). For example, in this issue, Haslam et al. (2006) review work showing that entity and essentialist theories can be successfully activated through reading brief fictitious scientific articles supporting essentialism or entity (and incremental theories) and impact responses in ways similar to when these lay theories are simply assessed by self-report, as just noted (e.g. Chiu, Hong et al., 1997; Haslam \& Ernst, 2002; Levy et al., 1998; Plaks et al., 2000). Using the same methodology, in this issue, Levy et al. (2006) had participants read a brief article allegedly from a prestigious university supporting or opposing the Protestant work ethic (PWE; hard work leads to success). Results from this experiment converged with those of a correlational study in which participants' reported their agreement with PWE. When a lay theory is activated in these ways, it is assumed that people can rather readily switch to viewing their world through the activated lay theory and rendering relevant judgments because the activated lay theory is familiar to them through previous social experiences (e.g. Dweck et al., 1995b; Hong et al., 2001). How long such a brief activation can last has not been tested for these lay theories.

Lay theories that are frequently activated, however, are expected to become chronically accessible (Dweck et al., 1995b; Hong et al., 2001) and become a possession (Abelson, 1986). The stability of lay theories, however, tends to be assumed or implied rather than formally tested. For example, as noted in the section on degree of universality of lay theories, lay theories are prevalent in some cultures and thus may be more stable in some environments. In this issue, Levy et al. (2006) suggest that the PWE and other lay theories with more than one intergroup meaning in a given culture may be especially stable across situations and over time. Because people can use the same lay theory (e.g. PWE) to support tolerance or intolerance across a wide variety of contexts, 'they do not need to give up the lay theory when the social implications are not relevant or appropriate in a particular context' (Levy et al., p. 112).

In addressing issues of stability, prior work as well as work in this Special Issue has also implied that lay theories and intergroup processes are mutually sustaining. That is, numerous lay theories have been shown to lead to particular intergroup attitudes and behaviors, in addition to being influenced by intergroup experiences and other contextual variables. There is some indirect evidence that the entity theory and stereotyping are mutually sustaining. Levy et al. (1998) showed that activating the entity theory activated greater stereotyping while Hong et al.'s (1999) findings suggest that greater exposure to stereotypes in the mass media contributed to 
greater agreement with the entity lay theory. Moreover, in this issue, Jayaratne et al. (2006) seem to suggest that discussions of genetic explanations in the mass media can reinforce prejudiced attitudes and vice versa. Furthermore, Sommers's and Norton's (2006) theorizing in this issue seems to suggest that for some Whites, their lay theories of White racists and behavior toward African Americans are mutually sustaining; they behave in 'racist' ways but define White racism in a way that excludes that behavior and thus continue their 'racist' behavior and so forth.

Research, then, shows that lay theories may be activated and deactivated in particular situations and contexts. Although theorized to also be relatively stable and part of mutually sustaining cycles with intergroup processes, little research has directly addressed these issues.

\section{Range of applicability}

Lay theories are thought to have a definite range of application or convenience (e.g. Kelly, 1955). Some theories are general while others are narrow. As examples, lay theories can be specific to the intergroup domain and to a particular group such as lay theories of White racists (Sommers \& Norton, 2006), or broader and apply to the intergroup domain as well as to self and interpersonal domains such as theories about the malleability of human attributes (Dweck, 1999; Dweck et al., 1995a; also see Haslam et al., 2006). Broad and pervasive lay theories likely impact a wide range of group processes and behaviors across many situations and over time. More specific lay theories likely have a narrower range of use, but nonetheless may be powerful predictors of intergroup processes and behavior within the theory's range of applicability.

Nevertheless, a lay theory derives its impact not only from its literal meanings, but also from the inferences it affords and its implications for social practices. Some lay theories have one set of commonly accepted meanings whereas others have two or more meanings. For example, the entitativity theory may entail the presence of common traits and a high level of homogeneity in the group, or alternatively the presence of common goals and high levels of group cohesiveness (e.g. Brewer, Hong, \& Li, 2004; Ip et al., in press). When a lay theory possesses dual meanings, the presence of contextual cues may evoke one or the other meaning (presence of common skin color among group members evokes the homogeneity sense of entitativity, whereas presence of common actions among group members evokes the cohesiveness sense of the same theory), pushing group inferences in one or the other direction (Ip et al., in press).

Several studies reported in this Special Issue illustrate how a lay theory's meanings can change with experience and context such that a lay theory can have two opposing intergroup meanings (see Levy, West, \& Ramirez, in press). For example, in this issue, Jayaratne et al. (2006), using a representative sample of US Whites, showed that genetic lay theories support prejudice toward Blacks but tolerance toward gay men and lesbians (also see Haslam et al., 2002; Haslam \& Levy, in press). Additionally, in this issue, Sommers and Norton (2006) uncovered multiple components to lay theories of White racism: one component focuses on 'subtle, ambiguous forms of bias, and attributes racism to intrinsic antecedents such as political ideology' and another narrower component focuses on external characteristics of White racists and 'seems to be a more contextdependent conceptualization, in which people consider mitigating nonracial factors that could account for potentially biased behavior' (p. 132). Furthermore, in this issue, Levy et al. (2006) showed that although the Protestant work ethic is associated with intolerance among US White adults (as past work has shown), it also is associated with egalitarianism among US children and early adolescents.

\section{Degree of universality}

Some lay theories are more widely shared or distributed in a given population. For instance, similar ratings of the entitativity of groups are reported from the United States and Poland (Lickel et al., 2000). Further, entity and incremental theories appear to relate to group perception in consistent ways in Australia, Hong 
Kong, and the US (e.g. Bastian \& Haslam, in press; Hong et al., 2004; Levy et al., 1998) and also among US adults and children (e.g. Karafantis \& Levy, 2004; Levy \& Dweck, 1999; Levy et al., 1998). Gender differences are rarely mentioned in this work.

At the same time, researchers have uncovered national differences in the way lay theories operate across and within nations (e.g. Morris, Menon, \& Ames, 2001; Yzerbyt, Corneille, \& Estrada, 2001). For instance, pertaining to essentialism, Mahalingam and Rodriquez (2003) showed that Indian men higher up in the caste system adhere more strongly to an essentialist view of women, compared to North Americans and other Indians. Kashima et al. (2005) reported stronger belief in group agency in East Asian countries or regions than in countries with a dominant European cultural tradition (Australia, Belgium, Germany, UK, US). Although entity theory of personality is equally popular in Hong Kong and the US (e.g. Chiu, Dweck, Tong, \& Fu, 1997), entity theory of society and its institutions is more widely distributed in Hong Kong than in the US (Chiu \& Hong, 1999; Chiu, Dweck, et al., 1997). This pattern of differences reflects the relatively more widespread belief in the US that society can be changed to accommodate the individual, and a relatively more popular belief in Hong Kong that individuals can change themselves to fit in with a fixed world (Chiu, Morris, Hong, \& Menon, 2000; Menon, Morris, Chiu, \& Hong, 1999; Su et al., 1999).

Cross-national comparison also reveals differences in the meaning of lay theories. PWE does not necessarily have the same intergroup significance in all cultures (e.g. Crandall \& Martinez, 1996). In a study of Colombians of age groups similar to those investigated by Levy et al. (2006) in this issue, Levy, Ramirez, and Velilla (2005) found that PWE has a predominately egalitarian meaning; that is, it does not appear to have the justifier of inequality meaning among Colombians.

Within-nation work also reveals variations in the way certain lay theories are understood and used. For example, as mentioned, in studies of essentialism, Mahalingam and Rodriguez
(2003) found significant social class differences in the tendency to essentialize the female gender. A lay theory also may have a different meaning depending on the ethnicity of the lay theorist. Following up on Levy et al.'s (2006) findings in this issue, Levy et al. (2005) found that PWE has a predominately egalitarian meaning among US Black and Latino adults while it additionally has a justifier of inequality meaning among US White adults. Although PWE (hard work leads to success) suggests a positive pathway to success for all members of society, it also can be utilized by relatively advantaged group members to justify the status quo. Likewise, No and Hong (2005) found that endorsement of a theory of fixed race (i.e. the belief that race is biologically determined and immutable) is positively related to social dominance orientation and symbolic racism among White Americans, but not among Asian Americans, possibly because the theory of fixed race has different significations among numerical majority and minority groups in the US. To White Americans, the theory legitimates their dominance, whereas to Asian Americans, the theory reminds them of an impermeable intergroup boundary and the obstacles to social mobility (see also Chao \& Hong, 2005).

Studies examining children's lay theories relevant to intergroup relations have tended to examine how early the lay theories emerge and have not uncovered age differences in the use of lay theories (e.g. Gelman, 2003; Hirschfeld, 1995). Research on entity and incremental theories with younger participants tends to replicate work with adults showing that the lay theories emerge early in life and are used in the same way across age groups (see Levy et al., 2001). Yet, in this issue, Levy et al. (2006) showed that PWE appears to function differently for White Americans of different ages. Compared to older groups (college age and adult community), who seem to have the flexibility to use either the egalitarian meaning or justifier of inequality meaning of PWE, younger groups (10- to 15-year-olds) seem to use the egalitarian meaning of the Protestant work ethic more often. The justifier of inequality meaning of PWE is probably less pervasive in 
the environments of young children, and children unlikely are as motivated as adults to use the justifier of inequality meaning of PWE.

To summarize this section on conceptual parameters of lay theories, it is increasingly clear that lay theories do not fall into a monolithic category. All people have some sort of lay theories; yet, level of endorsement of a lay theory or use of a particular meaning of a lay theory can vary across populations and contexts. When a lay theory or its meaning is widely shared in a particular group, it becomes a symbolic element in the group's shared reality or cultural worldview. The theory would likely be referenced frequently in everyday communication, and its meaning would likely be embodied in the group social, political, and educational institutions (e.g. Kashima, 2000; Lau, Chiu, \& Lee, 2001; Lau, Lee, \& Chiu, 2004). The theory will also be accorded with higher validity (e.g. Sechrist \& Stangor, 2001), and become particularly useful for reducing epistemic uncertainty (e.g. Kruglanski, Shah, Pierro, \& Mannetti, 2002) and existential anxiety (e.g. Halloran \& Kashima, 2004). Such functions are elaborated in the next section.

\section{Functions of lay theories}

Guided by an intuitive scientist metaphor, lay theories are thought to function primarily as providing epistemic functions (e.g. for reviews, see Fletcher, 1995; Furnham, 1988; Hong et al., 2001; McGarty, Yzerbyt, \& Spears, 2002; Wegener \& Petty, 1998). Lay theories are increasingly being shown to also serve important psychological and social functions.

\section{Understanding and simplification}

In their original operationalization, lay theories were expected to provide understanding and simplification akin to scientific theories (Heider, 1958; Kelly, 1955; Piaget \& Garcia, $1983 / 1989)$. Indeed, lay theories have been referred to as sense-making (e.g. McGarty, et al., 2002; Yzerbyt et al., 1997) and meaning systems (e.g. Chiu, Dweck, et al., 1997; Dweck \& Leggett, 1988; McGarty et al., 2002). Relatedly, lay theories are thought to simplify one's social world by imposing 'psychologically meaningful constraints on the infinite variety of interpretations available for a particular stimulus or event (Levy et al., 2001, p. 157, see Chiu et al., 2000; Demoulin et al., 2006; McGarty et al., 2002).

Additionally, offering a ready explanatory framework, a lay theory can be used to make relatively quick group judgments, and prior work shows that lay theories are indeed used when perceivers are under cognitive load (e.g. Knowles, Morris, Chiu, \& Hong, 2001) or time pressure (e.g. Chiu et al., 2000). The lay theories of White racism described by Sommers and Norton (2006) in this issue seem an especially good candidate for conserving cognitive energy. People can use their lay theory of White racism to take stock of others, making quick judgments of whether someone is racist or not and then taking action accordingly.

\section{Control}

A sense of psychological control often accompanies reduction of epistemic uncertainty. Lay theories as explanatory frameworks on how the world works or should work likely provide lay perceivers with a sense of control over their outcomes. Entity and incremental theories can provide lay theorists with a sense of control over their intergroup relations. People holding an entity theory likely gain a sense of control by sizing up which groups are 'good' versus 'bad' and thus which should be approached versus avoided (Hong et al., 2004). People holding an incremental theory, that people can change, likely feel a sense of control in their personal ability and ability of intervening circumstances to alter poor intergroup relations. Likewise, people who endorse PWE can feel a sense of control that by putting forth sufficient effort, they will achieve success (see e.g. Lied \& Pritchard, 1976). Also, according to the belief in a just world, a lay perceiver can insure positive outcomes through good behavior (e.g. Lerner, 1970; Montada, 1998). In addition, members of more advantaged groups may gain a sense of control by subscribing to lay theories such as belief in a just world (e.g. Montada, 1998), PWE (Levy et al., 2006), and genetic lay theories (e.g. Jayaratne et al., 2006) 
especially when they are used to justify and maintain their relatively advantaged place in society.

\section{Experiences and accuracy}

Lay theories may serve people's needs to label their observations and to see their experiences as reflecting a correct social reality. As noted earlier, some lay theories may represent narrative representations (Wyer, 2004). As such, lay theories may reflect people's observations and experiences and additionally seem to reflect an accurate view of one's social world. Although lay theories confer feelings of understanding and predictability, as noted earlier, they unlikely reflect an accurate picture of the world. Indeed, unlike scientific theories, they are unlikely put to a rigorous test for accuracy plus lay perceivers often hold conflicting lay theories. Nonetheless, people need to label their observations and experiences and to see their experiences as reflecting a correct social reality. The pervasive nature of certain lay theories and the process of people observing confirmatory evidence (see Fletcher, 1995 for a review) and communicating their lay theories to one another may create a sense of legitimacy and 'realness' to lay theories (e.g. Kashima, 2004).

Additionally, perceivers often attribute high levels of validity to lay theories that align with popular beliefs in the group (Sechrist \& Stangor, 2001) or in line with authority or scientific theories. Also, lay theories that appear to be closely in line with scientific theories may seem to fulfill needs for accurate observation of one's world. For example, in this issue, Jayarante et al. (2006) note that 'genetic lay theories parallel high-profile scientific discoveries that can have special standing as "valid" theories' (p. 79). Furthermore, lay theories perceived to be characteristic of a group are often used to define the prototype of the group (Hogg, 2004).

\section{Social utility}

Lay theories also seem to serve the additional function of social utility as they are not held by a single individual; indeed, this is why they are referred to as 'common sense' theories (e.g. see Fletcher, 1995). Lay theories can be quite pervasive in a given environment, as reviewed earlier, and hence are exchanged and shared by others in one's environment (e.g. see Fletcher, 1995; Furnham, 1988; McGarty et al., 2002). Shared lay theories, being integral parts of a group's shared socialization, have the potential to foster and maintain social relationships, express one's identification with the group (e.g. Jetten, Postmes, \& Mcauliffe, 2002), and satisfy the need for belongingness (e.g. Castano, Yzerbyt, Paladina, \& Sacchi, 2002; Pickett, Bonner, \& Coleman, 2002).

\section{Values}

As noted earlier, some lay theories can have both descriptive and prescriptive elements, for example, the third subtype of ontological assumptions. Therefore, some lay theories can be seen as fulfilling important values and serving as action guides. For example, PWE, in its prescriptive form, suggests that people should work hard and additionally, in its original form, included a disdain for leisure (Weber, 1904-1905/1958). Likewise, the belief in a just world, in its prescriptive form suggests that good deeds will be rewarded (e.g. see Stevens \& Fiske, 1995). As captured by proverbs relevant to the just world belief, 'What goes around comes around'; therefore, 'treat others as you would like to be treated'. The colorblind theory that race differences are superficial, irrelevant, and uninformative bases to make judgments of people (e.g. Richeson \& Nussbaum, 2004) suggests the prescription that people should be treated equally, thereby fitting with core values of numerous countries including the US (e.g. Kluegel \& Smith, 1986).

\section{Self- and group-protection}

Finally, articles in this Special Issue highlight that people may use lay theories to justify their intergroup attitudes and prevailing social inequalities (also see Jost \& Major, 2001; Sidanius \& Pratto, 1999). Specifically, people may use lay theories to justify their preexisting (high or low) levels of prejudice (e.g. Crandall, 2000; Sidanius \& Pratto, 1999; McGarty et al., 
2002; Yzerbyt et al., 1997). As one example, in this issue, Jayarante et al. (2006) note that 'genetic lay theories act as a rationale for reducing hostility toward gay men and lesbians for what is generally considered sociallyunacceptable behavior' (p. 82; Haslam \& Levy, in press; also see Keller, 2005). Furthermore, in this issue, Denson et al. (2006) noted that lay theories of groups such as entitativity and essentialism can be used to justify collective blaming and retaliating against group members who do not have a strong connection to an event that preceded the intergroup conflict.

Sommers and Norton (2006, p. 119), in this issue, also proposed that in the face of 'the uniquely polarizing and controversial nature of ideas about race (...) people's theories of racism tend to be constructed in ways that allow them to maintain a safe distance from any appearance of personal bias'. Similarly in this issue, Levy et al. (in press) noted that the justifier of inequality meaning was especially fitting to the relatively advantaged White participants in their studies. PWE also more generally confers self-esteem to those with positive outcomes (e.g. Quinn \& Crocker, 1999). Likewise, a belief in a just world can confer positive self-regard for the more socially and economically advantaged (e.g. Dzuka \& Dalbert, 2002; Hunt, 2000).

Taken together, lay theories serve important cognitive, social, and psychological functions for perceivers. Some lay theories may serve all these functions and other lay theories predominately one (e.g. Fletcher, 1995; Furnham, 1988). Some lay people hold opposing lay theories (e.g. Dweck et al., 1995a; Furnham, 1988), affording them the opportunity to utilize the one that best suits their needs in a given situation. Despite a long-standing functional analysis of lay theories, the functions of lay theories are generally assumed or implied rather than directly tested. More research is needed on functions, and research included in this Special Issue seems to be heading in the direction of more directly studying the functions of lay theories.

\section{Implications of lay theories for group processes and intergroup relations}

There are numerous types of groups, and research by Lickel and colleagues (Lickel et al., 2000, 2001) reveals that lay perceivers roughly distinguish between four types of groups: intimacy groups (e.g. friends), social categories (e.g. gender, race), task groups (e.g. coworkers), and loose associations (e.g. people waiting in a line). Nonetheless, most of the research has focused on positive and negative effects that lay theories have on social categories. Below, we provide a brief and limited review of the impact of lay theories on ingroups and outgroups.

\section{Implications for ingroups}

Lay theories have numerous positive benefits for individuals (e.g. providing understanding, meaning, simplification, and prediction) as well as for their groups. Shared lay theories may help foster and maintain intragroup relations through increased ingroup identification (e.g. see Castano, 2004) and greater attributions to shared human emotions (e.g. Leyens et al., 2001). In addition, lay theories may help group members collectively enjoy positive outcomes and keep negative ones at a distance, as noted earlier. As examples, lay theories can bolster the self-esteem of group members who are experiencing positive outcomes (e.g. PWE, Quinn \& Crocker, 1999; belief in a just world, Montada, 1998), allow group members to maintain a positive image of themselves despite prejudice (e.g. lay theories of White racism, Sommers \& Norton, 2006), and help justify one's group's relatively advantaged societal position (e.g. PWE, Levy et al., 2006).

Lay theories additionally may have negative effects on ingroup members, although evidence is limited. As one exception, Lickel, Schmader, Curtis, Scarnier, and Ames (2005) showed that the more interdependent (or entitatively) people viewed their group, the more they experienced vicarious guilt for a wrong-doing. In this issue, Denson et al. (2006) further noted that viewing one's group as highly entitative could lead to greater punishment of the 
ingroup wrongdoer. A lay theory could also conflict with self and group interests when it is too rigidly applied in intergroup contexts. For instance, a group leader rigidly viewing a group as highly entitative might refuse to negotiate with a benevolent outgroup because a few members behaved in an undesirable way on one occasion. As another example, group members rigidly adhering to an incremental theory may delay forming a negative impression and taking action against an otherwise clearly threatening outgroup. In addition, perceivers might hold onto a lay theory that does not serve their ingroup interests because the lay theory is prevalent in their culture and, hence, difficult to reject (e.g. see Jost \& Major, 2001).

\section{Implications for outgroups}

Some lay theories foster positive intergroup relations. As one example, an incremental (relative to an entity) theory has been shown to have mainly positive implications for outgroup perception, judgment, and behavior. People holding an incremental (vs. entity) theory tend to form weaker negative outgroup impressions that take into account context-sensitive factors (e.g. Hong et al., 2004; Levy \& Dweck, 1999) and that are updated in the face of disconfirming evidence (e.g. Plaks et al., 2000). Thus, perceivers with an incremental (vs. entity) theory in mind are reluctant to take action against outgroup members who behaved undesirably on one or two occasions (e.g. Levy \& Dweck, 1999) and provide greater help to groups who are socially stigmatized (e.g. Karafantis \& Levy, 2004).

In contrast, an entity theory has been portrayed as a lay theory having mostly negative intergroup implications. Individuals operating under an entity theory framework tend to look for evidence of the expression of negative traits in the behaviors of outgroup members, including evidence that confirms knowledge of societal stereotypes (e.g. Eberhardt, Dasgupta, \& Banaszynski, 2003; Plaks et al., 2000). Perceivers holding an entity (vs. incremental) theory also generate more trait attributions for group members' behaviors (e.g. Levy \& Dweck, 1999; Levy et al., 1998), have a greater tendency to use evaluative traits to categorize individuals (Tong \& Chiu, 2002), perceive greater withingroup variance and between-group commonalties (e.g. Levy \& Dweck, 1999; Levy et al., 1998), make more extreme trait judgments of racial, ethnic, occupational, and unfamilar groups (Bastian \& Haslam, in press; Levy \& Dweck, 1999; Levy et al., 1998), exhibit greater prejudice toward recent immigrants or racial minorities (Hong et al., 2004), report less willingness to socialize with others who exhibited a few negative and neutral behaviors (e.g. Levy \& Dweck, 1999), and provide less help for disadvantaged others (Karafantis \& Levy, 2004).

Research on entity and incremental theories also shows that their use depends on the cultural context and lay perceiver, as noted earlier. Increasingly, however, many other lay theories are being shown to have mixed implications for intergroup relations, fostering positive or negative outgroup implications depending on the lay perceiver, target group, and context (e.g. Levy, West, \& Ramirez, in press). For example, essentialism has been found to be related to greater dispositional judgments (e.g. Yyzerbyt et al., 1997, 2001), greater anti-gay attitudes (e.g. Haslam et al., 2002; Haslam \& Levy, in press), and seeing outgroups as less human (e.g. Paladino, Vaes, Castano, Demoulin, \& Leyens, in press). At the same time, essentialism in some forms is related to more positive attitudes toward gay men and lesbians (e.g. Haslam et al., 2002; Haslam \& Levy, in press).

Relatedly, in this issue, Jayaratne et al. (2006) showed that US Whites holding genetic lay theories would be concerned if their (hypothetical) child dated or married an African American, and Keller (2005) showed that a belief in genetic determinism was related to greater sexism and racism. However, in this issue, Jayaratne et al. (2006) showed that the more lay perceivers endorsed a genetic theory to account for differences in sexual orientation, the less bothered they were that their (hypothetical) son or daughter was homosexual.

In a similar vein, on one hand, highly entitative groups compared to low entitative groups are evaluated more strongly with more implicit intragroup comparison (e.g. Pickett, 2001) and 
greater attributions to negative dispositions (e.g. Abelson, Dasgupta, Park, \& Banaji, 1998; Dasgupta, Banaji, \& Abelson, 1999; McConnell, Sherman, \& Hamilton, 1997; Yzerbyt et al., 1997, 1998). Highly entitative groups also receive greater levels of collective responsibility for negative acts including murder (e.g. Denson et al., 2006; Lickel, Schmader, \& Hamilton, 2003). On the other hand, McConnell and colleagues (e.g. McConnell et al., 1997) have shown that people engage in more effortful and elaborative information processing of highly entitative groups, and hence strong arguments of highly entitative groups are viewed as more persuasive, leading to greater attitude change (Rydell \& McConnell, 2005).

For a lay theory with more than one intergroup meaning, the context may set the stage for which meaning is used. For example, when the 'justifying disadvantage' aspect of the PWE and belief in a just world is salient, these lay theories have negative effects on disadvantaged outgroups and their members. Endorsement of PWE has been shown to relate to stronger negative attitudes toward African Americans (e.g. Katz \& Hass, 1988; also see Biernat et al., 1996), dislike of overweight persons (e.g. Crandall, 1994), negative attitudes toward homeless persons (e.g. Levy et al., 2002; Somerman, 1993), negative affect toward people facing AIDS (e.g. Levy et al., 2002), less desired social distance toward African Americans (e.g. Levy et al., 2006), opposition to a community facility for homeless families (e.g. Somerman, 1993), and less donated money to a homeless shelter (e.g. Levy et al., 2006). Lay perceivers holding the just world belief tend to exhibit negative affect toward victims (e.g. fictitious female alleged victim of gender discrimination, Jost \& Burgess, 2000) and blame people for their plights (e.g. rape victims, people facing AIDS and homelessness, cancer patients; e.g. Montada, 1998). Yet, when the egalitarian aspect of PWE is salient, it attenuates intergroup animosity and is associated with reported egalitarianism and desired social closeness to African Americans (Levy et al., 2006). Likewise, the belief in a just world, should lead to fair treatment of others in some circumstances when its prescriptive form (good deeds will be rewarded) is salient (e.g. see Stevens \& Fiske, 1995).

It is important to highlight that lay theories have not only been associated with numerous indicators of intergroup relations, but lay theories are powerful predictors of these indicators, explaining a large proportion of the variance (e.g. Haslam et al., 2002). Some studies, have shown that lay theories are even more powerful predictors than relevant personality and cognitive variables. For example, Levy et al. (1998) showed that entity theory (relative to incremental theory) predicted ethnic and occupational stereotyping independently of individual difference variables (e.g. right-wing authoritarianism, need for cognitive closure, attributional complexity, need to evaluate) and also its unique predictive contribution was larger than each of them. Similarly, Bastian and Haslam (in press) showed that essentialism (with a measure including some entity theory items) predicted stereotyping independent of and more strongly than the same individual variables including social dominance orientation (Pratto, Sidanius, Stallworth, \& Malle, 1994).

In summary, the implications of lay theories for ingroups and especially outgroups are extensive. Yet, there does not appear to be a simple relation between a lay theory and tolerance or intolerance; the implications depend on the target group, context, and lay perceiver. This underscores the proposition that lay theories are not a monolithic theoretical construct. This also suggests that utilizing lay theories as part of a prejudice reduction effort (e.g. highlighting a lay theory with egalitarian implications) would require a consideration of the interplay between the lay perceivers' needs, the context, and the target group.

\section{Interrelations among lay theories}

With the abundance of research on lay theories and group processes, researchers have begun to compare and contrast seemingly related lay theories and take steps toward a synthesis. A prominent example, as highlighted in this 
Special Issue, is work on several complementary lay theories generally concerning the extent to which human groups are seen as having a core, underlying, fixed, or essential qualities or that groups and their members are malleable and vary across time and situations, including work on entatitivity (e.g. Brewer \& Harasty, 1996; Brewer et al., 2004; Demoulin et al., 2006; Denson et al., 2006; Hamilton \& Sherman, 1996; Haslam et al., 2000; Lickel et al., 2000; McGarty, Haslam, Hutchinson, \& Grace, 1995; Yzerbyt et al., 2004), essentialism (e.g. Demoulin et al., 2006; Denson et al., 2006; Haslam et al., 2000, 2006, Rothbart \& Taylor, 1992; Yzerbyt et al., 1997), entity versus incremental theories (e.g. Dweck et al., 1995a; Haslam et al., 2006; Levy et al., 1998), and genetic lay theories (e.g. Jayaratne et al., 2006; also see Keller, 2005).

Indeed, these lay theories share not only conceptual overlap but predictive validity as reviewed in the previous section. Accordingly, there is a growing agreement to work toward integrating this work, as exemplified by a recent, substantial edited volume on the topic (Yzerbyt et al., 2004) as well as by articles in this Special Issue. Facilitating the exploration of the overlap, some laboratories are working toward common definitions of each of these lay theories and, thus, using similar measures of them (e.g. Bastian \& Haslam, in press; Demoulin et al., 2006; Haslam et al., 2006). At the same time, as illustrated in this Special Issue, researchers are using multiple measures of each lay theory across studies and showing that variations in the operationalization of the lay theory does not necessarily alter the pattern of findings (e.g. Demoulin et al., 2006; Denson et al., 2006).

This is not to imply that there is agreement on whether entity, entitativity, essentialism, or genetic lay theories are distinct lay theories or whether one or more of them is a broader lay theory including one or more of the others. There does appear to be a consensus that entitativity and natural kinds (or inalterability; a form of essentialism) are separate, albeit related, lay theories or subcomponents (e.g. Haslam et al., 2000; Yzerbyt et al., 2001; also see
Rothbart \& Taylor, 1992). In this issue, Denson et al.'s (2006) work on collective responsibility judgments suggests that entitativity and essentialism (defined as inalterability or natural kinds) are separate lay theories. Also in this issue, Demoulin et al. (2006) showed that forced choice categories (e.g. race, gender) tend to be viewed as natural kinds whereas social choice categories (e.g. major course of study, political party affiliation) tend to be viewed in terms of their entitativity. However, when essentialism is defined more broadly, entitativity and natural kinds tend to be considered subcomponents of essentialism (e.g. Demoulin et al., 2006; Haslam et al. 2000). So, one burning question is how broadly to define essentialism and, relatedly, is it the overriding lay theory of this group of related constructs?

There are also remaining questions about how to best define entitativity and natural kinds. For example, in this issue, Demoulin et al. (2006) defined entitativity in a rather broad way, including common goals, common fate, similarity, groupness, interaction, informativeness, and importance, dimensions drawn from prior measures (Haslam et al., 2000; Lickel et al., 2000; also see Dasgupta et al., 1999). Also in this issue, Denson et al. (2006, Study 2) in one study defined entitativity in a broad, albeit slightly different way (uniformity, informativeness, exclusivity, interaction, common goals), drawing from similar prior measures (Haslam et al., 2000; Lickel et al., 2003). Denson et al. (2006, Study 1) in a different study, showed that defining entitativity in a more narrow way as 'interdependence' (interaction, behavioral influence, norms, interpersonal bonds, shared knowledge, common goals, e.g. Lickel et al., 2000) did not significantly alter the pattern of findings. Other recent research, though, has found entitativity to consist of two distinct components: perceived homogeneity and perceived cohesiveness or agency (e.g. Brewer et al., 2004; Ip et al., in press; Kashima et al., 2005), and thus synthesizing definitions of entitativity is still underway.

Regarding natural kinds, Haslam and colleagues (Haslam et al., 2006; also see Bastian \& Haslam, in press) in this issue suggest that 
entity theory is part of a natural kinds factor of essentialism because both concern 'immutability'. Using items from an entity theory scale used in prior work (e.g. Levy et al., 1998), Bastian and Haslam (in press) showed that that natural kinds items and entity items were intercorrelated and further that the entity items loaded on a factor including biological basis, informativeness, and discreteness. Also, the entity theory dimension did not outperform the other three dimensions (biological basis, informativeness, discreteness) in terms of stereotype endorsement although it did outperform them in terms of predicting innate explanations for stereotypes.

Immutability has not only received special attention through the study of natural kinds or entity theory (vs. incremental theory), but also by two relatively newer lay theories. For example, Keller (2005) introduced a belief in genetic determinism (biological component of essentialism) and found it to be significantly correlated with an entity theory and an entitativity index (Haslam et al.'s, 2000, measure), although marginally related to a natural kinds index (Haslam et al.'s, 2000, measure). In a similar vein, in this issue, Jayaratne et al. (2006) introduced genetic lay theories, noting conceptual overlap to essentialism (namely natural kinds dimension), entity theory, and belief in genetic determinism. It remains to be tested the extent to which an entity theory, belief in genetic determinism, and genetic lay theories overlap with one another and whether they are encompassed by essentialism more generally (e.g. Haslam et al., 2006) or are better viewed as distinct from other aspects of essentialism.

Although efforts to synthesize research on conceptually related lay theories has focused on the lay theories just mentioned, other lay theories relevant to group processes share conceptual overlap. For example, PWE and belief in a just world converge in suggesting that outcomes are determined by an individual's behavior. The belief in a just world suggests that an individual who does good deeds will reap benefits, and PWE suggests that an individual who works hard will achieve success. Just world belief focusing on the 'world' is more general than PWE, which is a more narrowly confined context of 'work'. As reviewed in the above section, PWE and just world belief share predictive validity, and there is empirical evidence for their conceptual overlap (e.g. Furnham \& Rajamanickam, 1992). More work is needed on these similar lay theories.

To summarize, researchers have identified sets of complementary lay theories predicting similar group processes. Accordingly, researchers are refining their conceptualizations of individual lay theories and working toward distinguishing them. The substantial conceptual and predictive overlap between lay theories suggests that they are part of an associative network and likely collectively influence group and intergroup processes.

\section{Conclusion}

Research on lay theories and intergroup relations, broadly defined, is rapidly growing. The contributors to this Special Issue on the topic include international scholars from different intellectual traditions cutting across social, cognitive, personality, developmental, and cultural psychology. Their work showcases the latest developments in this area while also suggesting fruitful future directions of research.

Articles in this issue contribute to a more refined definition of lay theories. Lay theories have traditionally been discussed as lay people's scientific theories. Recent work confirms similarities between scientific theories and lay theories while also shedding light on some key differences between them. Lay theories share structural and functional qualities as well as content with scientific theories. However, unlike scientific theories, lay theories need not be objective, testable, or true. Lay theories may be adopted to serve the self and to justify the state of affairs.

In addition, this research suggests that lay theories are not monolithic. They differ in terms of type of representation, level of articulation, frequency of activation and use, range of applicability, and degree of universality. Therefore, it has becoming increasingly pressing to 
consider the similarities and differences among lay theories. For that reason, researchers are comparing and contrasting seemingly related lay theories. The identification of lay theories relevant to intergroup relations will likely continue in parallel and in connection to a movement toward synthesizing related lay theories into a smaller set.

Furthermore, as research on lay theories continues to blossom, the positive and negative implications of lay theories for ingroups and outgroups continue to be defined. Lay theories seem to serve perceivers and their ingroups by serving epistemic needs as well as social and psychological needs, although more work is needed directly testing the functions of lay theories. Lay theories can also have positive implications for outgroups. Nevertheless, a host of negative implications for outgroups as a function of perceivers' lay theories, have been identified, in keeping with the goal of many researchers who study lay theories as a vehicle for understanding intergroup conflict. Lay theories play a detrimental role in intergroup relations beginning with how outgroup information is encoded and processed and extending to negative affect, negative attributions, stereotyping, prejudice, and discrimination.

In conclusion, research continues to mount showing that people of all backgrounds use lay theories as key filters for a wide range of group processes across many types of intergroup relations and in countless environments. We look forward to the next wave of research in this area that moves us toward a fuller understanding of the nature of lay theories, while also contributing to a fuller understanding of the dynamics of intergroup relations.

\section{Acknowledgment}

This material is in part based upon work supported by the National Science Foundation under Grant No. 0213660 to the first author.

\section{References}

Abelson, R. P. (1986). Beliefs are like possessions. Journal for the Theory of Social Behavior, 16, 223-250.
Abelson, R. P., Dasgupta, N., Park, J., \& Banaji, M. (1998). Perceptions of the collective other. Personality and Social Psychology Review, 2, 243-250.

Bastian, B., \& Haslam, N. (in press). Psychological essentialism and stereotype endorsement. Journal of Experimental Social Psychology.

Biernat, M., Vescio, T. K., \& Theno, S. A. (1996). Violating American values: A 'value congruence' approach to understanding outgroup attitudes. Journal of Experimental Social Psychology, 32, 387-410.

Brewer, M. B., \& Harasty, A. S. (1996). Seeing groups as entities: The role of perceiver motivation. In R. M. Sorrentino \& E. T. Higgins (Eds.), Handbook of motivation and cognition (Vol. 3, pp. 347-370). New York: Guilford.

Brewer, M. B., Hong, Y., \& Li, Q. (2004). Dynamic entitativity: Perceiving groups as actors. In V. Yzerbyt, C. M. Judd, \& O. Corneille (Eds.), The psychology of group perception: Perceived variability, entitativity, and essentialism (pp. 25-38). New York: Psychology Press.

Castano, E. (2004). On the advantages of reifying the ingroup. In V. Yzerbyt, C. M. Judd, \& O. Corneille (Eds.), The psychology of group perception: Perceived variability, entitativity, and essentialism (pp. 381-400). New York: Psychology Press.

Castano, E., Yzerbyt, V., Paladino, M.-P., \& Sacchi, S. (2002). I belong, therefore, I exist: Ingroup identification, ingroup entitativity, and ingroup bias. Personality and Social Psychology Bulletin, 28, 135-143.

Chao, M. M., \& Hong, Y. (2005). Navigating between mainstream and ethnic minority cultures: A dynamic constructivist approach to intercultural processes. Manuscript under review.

Chiu, C-y., Dweck, C. S., Tong, J. Y., \& Fu, J. H. (1997). Implicit theories and conceptions of morality. Journal of Personality and Social Psychology, 73, 923-940.

Chiu, C-y., \& Hong, Y. (1999). Social identification in a political transition: The role of implicit beliefs. International Journal of Intercultural Relations, 23, 297-318.

Chiu, C-y., Hong, Y., \& Dweck, C. S. (1994). Toward an integrative model of personality and intelligence: A general framework and some preliminary steps. In R. J. Sternberg \& P. Ruzgis (Eds.), Personality and intelligence (pp. 104-134). Cambridge, UK: Cambridge University Press.

Chiu, C-y., Hong, Y., \& Dweck, C. (1997). Lay dispositionism and implicit theories of personality. Journal of Personality and Social Psychology, 73, 19-30. 
Chiu, C-y., Morris, M. W., Hong, Y., \& Menon, T. (2000). Motivated cultural cognition: The impact of implicit cultural theories on dispositional attribution varies as a function of need for closure. Journal of Personality and Social Psychology, 78, 247-259.

Crandall, C. S. (1994). Prejudice against fat people: Ideology and self-interest. Journal of Personality and Social Psychology, 66, 882-894.

Crandall, C. S. (2000). Ideology and ideologies of stigma: The justification of stigmatization. In T. F. Heatherton, R. E. Kleck, M. R. Hebl, \& J. G. Hull (Eds.), The social psychology of stigma (pp. 126-150). New York: Guilford.

Crandall, C. S., \& Martinez, R. (1996). Culture, ideology, and antifat attitudes. Personality and Social Psychology Bulletin, 22, 1165-1176.

Dasgupta, N., Banaji, M. R., \& Abelson, R. P. (1999). Group entitativity and group perception: Associations between physical features and psychological judgment. Journal of Personality and Social Psychology, 5, 991-1003.

Demoulin, S., Leyens, J.-P., \& Yzerbyt, V. (2006). Lay theories of essentialism. Group Processes $\mathcal{E}^{\circ}$ Intergroup Relations, 9, 25-42.

Denson, T. F., Lickel, B., Curtis, M., Stenstrom, D. M., \& Ames, D. (2006). The roles of entitativity and essentiality in judgments of collective responsibility. Group Processes and Intergroup Relations, 9, 43-61.

Dweck, C. S. (1999). Self-theories: Their role in motivation, personality, and development. Philadelphia, PA: Psychology Press.

Dweck, C. S., Chiu, C-y., \& Hong, Y. (1995a). Implicit theories and their role in judgments and reactions: A world from two perspectives. Psychological Inquiry, 6, 267-285.

Dweck, C. S., Chiu, C-y., \& Hong, Y. (1995b). Implicit theories: Elaboration and extension of the model. Psychological Inquiry, 6, 322-333.

Dzuka, J., \& Dalbert, C. (2002). Mental health and personality of Slovak unemployed adolescents: The impact of belief in a just world. Journal of Applied Social Psychology, 32, 732-757.

Eberhardt, J., Dasgupta, N., \& Banaszynski, T. (2003). Believing is seeing: The effects of racial labels and implicit beliefs on face perception. Personality and Social Psychology Bulletin, 29, 360-370.

Fletcher, G. (1995). The scientific credibility of folk psychology. Mahwah, NJ: Lawrence Erlbaum.

Furnham, A. (1988). Lay theories: Everyday understandings of problems in the social sciences. New York: Pergamon Press.

Furnham, A., \& Rajamanickam, R. (1992). The
Protestant work ethic and just world beliefs in Great Britain and India. International Journal of Psychology, 27, 401-416.

Gelman, S. A. (2003). The essential child: Origins of essentialism in everyday thought. London: Oxford University Press.

Halloran, M. J., \& Kashima, E. S. (2004). Social identity and worldview validation: The effects of ingroup identity primes and mortality salience on value endorsement. Personality and Social Psychology Bulletin, 30, 915-925.

Hamilton, D. L., \& Sherman, S. J. (1996). Perceiving persons and groups. Psychological Review, 103, 336-355.

Haslam, N., Bastian, B., Bain, P., \& Kashima, Y. (2006). Psychological essentialism, implicit theories, and intergroup relations. Group Processes E Intergroup Relations, 9, 63-76.

Haslam, N., \& Ernst, D. (2002). Essentialist beliefs about mental disorders. Journal of Social and Clinical Psychology, 21, 628-644.

Haslam, N., \& Levy, S. R. (in press). Essentialist beliefs about homosexuality: Structure and implications for prejudice. Personality and Social Psychology Bulletin.

Haslam, N., Rothschild, L., \& Ernst, D. (2000). Essentialist beliefs about social categories. British Journal of Social Psychology, 39, 113-127.

Haslam, N., Rothschild, L., \& Ernst, D. (2002). Are essentialist beliefs associated with prejudice? British Journal of Social Psychology, 41, 87-100.

Haslam, N., Rothschild, L., \& Ernst, D. (2004). Essentialism and entitativity: Structures of beliefs about the ontology of social categories. In V. Yzerbyt, C. M. Judd, \& O. Corneille (Eds.), The psychology of group perception: Perceived variability, entitativity, and essentialism (pp. 61-100). New York: Psychology Press.

Heider, F. (1958). The psychology of interpersonal relations. New York: Wiley.

Higgins, E. T. (1996). Knowledge activation: Accessibility, applicability and salience. In E. T. Higgins \& A. E. Kruglanski (Eds.), Social psychology: Handbook of basic principles (pp. 133-168). New York: Guilford.

Hirschfeld, L.A. (1995). Do children have a theory of race? Cognition, 54, 209-252.

Hogg, M. A. (2004). Social identity, selfcategorization, and communication in small groups. In S-h. Ng, C. N. Candlin, \& C-y. Chiu (Eds.), Language matters: Communication, culture, and identity (pp. 221-243). Hong Kong: City University of Hong Kong Press.

Hong, Y., Chiu, C-y., Dweck, C. S., \& Sacks, R. 
(1997). Implicit theories and evaluative processes in person cognition. Journal of Experimental Social Psychology, 33, 296-323.

Hong, Y., Chiu, C-y., Yeung, G., \& Tong, Y. Y. (1999). Social comparison during the political transition: Interaction of entity versus incremental beliefs and social identities. Journal of Intercultural Relations, 23, 257-279.

Hong, Y., Coleman, J., Chan, G., Wong, R. Y. M., Chiu, C., \& Hansen, I. et al. (2004). Predicting intergroup bias: The interactive effects of implicit theory and social identity. Personality and Social Psychology Bulletin, 30, 1035-1047.

Hong, Y., Levy, S. R., \& Chiu, C-y. (2001). The contribution of the lay theories approach to the study of groups. Personality and Social Psychology Review, 5, 98-106.

Hunt, M. O. (2000). Status, religion, and the 'belief in a just world': Comparing African Americans, Latinos, and Whites. Social Science Quarterly, 81, 325-343.

Ip, G. W-m., Chiu, C-y., \& Wan, C. (in press). Birds of a feather and birds flocking together: Physical versus behavioral cues may lead to trait- versus goal-based group perception. Journal of Personality and Social Psychology.

Jayaratne, T. E., Ybarra, O., Sheldon, J. P., Brown, T. N., Feldbaum, M., Pfeffer, C. A. et al. (2006). White Americans' genetic lay theories of race differences and sexual orientation: Their relationship with prejudice toward Blacks, and gay men and lesbians. Group Processes $\mathcal{E}$ Intergroup Relations, 9, 77-94.

Jetten, J., Postmes, T., \& Mcauliffe, B. (2002). 'We're all individuals': Group norms of individualism and collectivism, levels of identification and identity threat. European Journal of Social Psychology, 32, 189-207.

Jost, J. T., \& Burgess, D. (2000). Attitudinal ambivalence and the conflict between group and system justification motives in low status groups. Personality and Social Psychology Bulletin, 26, 293-305.

Jost, J. T., \& Major, B. (2001). The psychology of legitimacy: Emerging perspectives on ideology, justice, and intergroup relations. Cambridge, UK: Cambridge University Press.

Karafantis, D. M., \& Levy, S. R. (2004). The role of children's lay theories about the malleability of human attributes in beliefs about and volunteering for disadvantaged groups. Child Development, 75, 236-250.

Kashima, Y. (2000) Maintaining cultural stereotypes in the serial reproduction of narratives. Personality and Social Psychology Bulletin, 26, 594-604.
Kashima, Y. (2004). Culture, communication, and entitativity: A social psychological investigation of social reality. In V. Yzerbyt, C. M. Judd, \& O. Corneille (Eds.), The psychology of group perception: Perceived variability, entitativity, and essentialism (pp. 257-273). New York: Psychology Press.

Kashima, Y., Kashima, E., Chiu, C., Farsides, T., Gelfand, M., Hong, Y. et al. (2005). Culture, essentialism, and agency: Are individuals universally believed to be more real entities than groups? European Journal of Social Psychology, 35, 147-169.

Katz, I., \& Hass, R. G. (1988). Racial ambivalence and American value conflict: Correlational and priming studies of dual cognitive structures. Journal of Personality and Social Psychology, 55, 893-905.

Keller, J. (2005). In genes we trust: The biological component of psychological essentialism and its relationship to mechanisms of motivated social cognition. Journal of Personality and Social Psychology, 88, 686-702.

Kelly, G. A. (1955). The psychology of personal constructs. New York: Norton.

Kluegel, J. R., \& Smith, E. R. (1986). Beliefs about inequality: Americans'views of what is and what ought to be. New York: Aldine De Gruyter.

Knee, C. R., Patrick, H., \& Lonsbary, C. (2003). Implicit theories of relationships: Orientations toward evaluation and cultivation. Personality and Social Psychology Review, 7, 41-55.

Knowles, E., Morris, M. W., Chiu, C-y., \& Hong, Y. (2001). Culture and the process of person perception: Evidence for automaticity among East Asians in correcting for situational influences on behavior. Personality and Social Psychology Bulletin, 27, 1344-1356.

Kruglanski, A. W., Shah, J. Y., Pierro, A., \& Mannetti, L. (2002). When similarity breeds content: Need for closure and the allure of homogeneous and self-resembling groups. Journal of Personality and Social Psychology, 83, 648-662.

Lau, I. Y-M., Chiu, C-y., \& Lee, S-L. (2001). Communication and shared reality: Implications for the psychological foundations of culture. Social Cognition, 19, 350-371.

Lau, I., Lee, S-L., \& Chiu, C-y. (2004). Language, cognition and reality: Constructing shared meanings through communication. In M. Schaller \& C. Crandall (Eds.), The psychological foundations of culture (pp. 77-100). Mahwah, NJ: Erlbaum.

Lerner, M. J. (1970). The desire for justice and reactions to victims. In J. Macaulay \& L. Berkowitz 
(Eds.), Altruism and helping behavior. New York: Academic Press.

Levy, S. R., \& Dweck, C. S. (1999). The impact of children's static versus dynamic conceptions of people on stereotype formation. Child Development, 70, 1163-1180.

Levy, S. R., Freitas, A. L., \& Salovey, P. (2002). Construing action abstractly and blurring social distinctions: Implications for perceiving homogeneity among, but also empathizing with and helping, others. Journal of Personality and Social Psychology, 83, 1224-1238.

Levy, S. R., Plaks, J., Hong, Y., Chiu, C-y., \& Dweck, C. S. (2001). Static versus dynamic theories of groups: Different routes to different destinations. Personality and Social Psychology Review, 5, 156-168.

Levy, S. R., Ramirez, L., \& Vellila, E. (2005). The role of culture and context on the intergroup meaning of the Protestant work ethic. Unpublished manuscript. State University of New York at Stony Brook.

Levy, S. R., Stroessner, S. J., \& Dweck, C. S. (1998). Stereotype formation and endorsement: The role of implicit theories. Journal of Personality and Social Psychology, 74, 1421-1436.

Levy, S. R., West, T., \& Ramirez, L. (in press). Lay theories and intergroup relations:

A social-developmental perspective. In W. Stroebe \& M. Hewstone (Eds.), The European review of social psychology.

Levy, S. R., West, T. L., Ramirez, L., \& Karafantis, D. M. (2006). The Protestant work ethic: A lay theory with dual intergroup implications. Group Processes E Intergroup Relations, 9, 95-115.

Leyens, J. Ph., Rodriguez, A. P., Rodriguez, R. T., Gaunt, R., Paladino, P. M., Vaes, J. et al. (2001). Psychological essentialism and the differential attribution of uniquely human emotions to ingroups and outgroups. European Journal of Social Psychology, 31, 395-411.

Lickel, B., Hamilton, D. L., \& Sherman, S. J. (2001). Elements of a lay theory of groups: Types of groups, relational styles, and the perception of group entitativity. Personality and Social Psychology Review, 5, 129-140.

Lickel, B., Hamilton, D. L., Wieczorkowska, G., Lewis A., Sherman, S. J., and Uhles, N. (2000). Varieties of groups and the perception of group entitativity. Journal of Personality and Social Psychology, 78, 223-246.

Lickel, B., Schmader, T., Curtis, M, Scarnier, M., \& Ames, D. R. (2005) Vicarious shame and guilt. Group Processes and Intergroup Relations, 8, 145-157.

Lickel, B., Schmader, T., \& Hamilton, D. L. (2003). A case of collective responsibility: Who else was to blame for the Columbine High School shootings? Personality and Social Psychology Bulletin, 29, 194-204.
Lied, T. R., \& Pritchard, R. D. (1976). Relationships between personality variables and components of the expectancy-valence model. Journal of Applied Psychology, 61, 463-467.

Mahalingam, R., \& Rodriguez, J. (2003). Essentialism, power and cultural psychology of gender. Journal of Cognition $\mathcal{E}$ Culture, 3, 157-174.

McConnell, A. R., Sherman, S. J., \& Hamilton, D. L. (1997). Target entitativity: Implications for information processing about individual and group targets. Journal of Personality and Social Psychology, 72, 750-762.

McGarty, C., Haslam, S. A., Hutchinson, K., \& Grace, D. M. (1995). Determinants of perceived consistency: The relationship between group entitativity and the meaningfulness of categories. British Journal of Social Psychology, 34, 237-256.

McGarty, C., Yzerbyt, Y., \& Spears, R. (Eds.) (2002). The formation of social stereotypes. Cambridge, UK: Cambridge University Press.

Menon, T., Morris, M., Chiu, C-y., \& Hong, Y. (1999). Culture and attributions to individuals versus groups: North Americans attribute to personal dispositions; East Asians attribute to the dispositions of social collectives. Journal of Personality and Social Psychology, 76, 701-717.

Montada, L. (1998). Belief in a just world: A hybrid of justice, motive and self-interest. In L. Montada, \& M. Lerner (Eds.), Responses to victimizations and belief in the just world (pp. 217-245). New York: Plenum.

Morris, M. W., Menon, T., \& Ames, D. R. (2001). Culturally conferred conceptions of agency: A key to social perception of persons, groups, and other actors. Personality and Social Psychology Review, 5, 169-182.

Nisbett, R. E., \& Wilson T. D. (1977). Telling more than we can know: Verbal reports on mental processes. Psychological Review, 84, 231-259.

No, S., \& Hong, Y. (2005). Lay theory of race moderates cultural frame switching for mainstream culture primes among ethnic minority biculturals. Unpublished manuscript, University of Illinois at UrbanaChampaign.

Paladino, M-P., Vaes, J., Castano, E., Demoulin, S., \& Leyens, J-P. (in press). Emotional infra-humanization in intergroup relations: The role of national identification in the attribution of primary and secondary emotions to Italians and Germans. Cahiers de Psychologie Cognitive.

Piaget, J., \& Garcia, R. (1983/1989). Psychogenesis and the history of the sciences. (H. Fielder, Trans.) Paris: Flamarion. (Original work published 1983.)

Pickett, C. L. (2001). The effects of entitativity beliefs on implicit comparisons between group 
members. Personality and Social Psychology Bulletin, 27, 515-525.

Pickett, C. L., Bonner, B. L., \& Coleman, J. M. (2002). Motivated self-stereotyping: Heightened assimilation and differentiation needs result in increased levels of positive and negative self-stereotyping. Journal of Personality and Social Psychology, 82, 543-562.

Plaks, J. E., Grant, H., \& Dweck, C. S. (2005). Violations of implicit theories and the sense of prediction and control: Implications for motivated person perception. Journal of Personality and Social Psychology, 88, 245-262.

Plaks, J. E., Stroessner, S. J., Dweck, C. S., \& Sherman, J. (2000). Person theories and attention allocation: Preferences for stereotypic versus counter stereotypic information. Journal of Personality and Social Psychology, 80, 876-893.

Pratto, F., Sidanius, J., Stallworth, L. M., \& Malle, B. F. (1994). Social dominance orientation: A personality variable predicting social and political attitudes. Journal of Personality and Social Psychology, 67, 741-763.

Quinn, D. M., \& Crocker, J. (1999). When ideology hurts: Effects of belief in the Protestant ethic and feeling overweight on the psychological well-being of women. Journal of Personality and Social Psychology, 77, 402-414.

Richeson, J. A., \& Nussbaum, R. J. (2004). The impact of multiculturalism versus color-blindness on racial bias. Journal of Experimental Social Psychology, 40, 417-423.

Ross, M. (1989). The relation of implicit theories to the construction of personal histories. Psychological Review, 96, 341-357.

Rothbart, M., \& Taylor, M. (1992). Category labels and social reality: Do we view social categories as natural kinds? In G. R. Semin \& K. Fiedler (Eds.), Language and social cognition (pp. 11-36). London: Sage.

Rydell, R. J., \& McConnell, A. R. (2005). Perceptions of entitativity and attitude change. Personality and Social Psychology Bulletin, 31, 99-110.

Sechrist, G. B., \& Stangor, C. (2001). Perceived consensus influences intergroup behavior and stereotype accessibility. Journal of Personality and Social Psychology, 80, 645-654.

Sidanius, J., \& Pratto, F. (1999). Social dominance: An intergroup theory of social hierarchy and oppression. New York: Cambridge University Press.

Somerman, F. B. (1993). Value, attitude, and belief determinants of willingness to accept a facility for the homeless. Journal of Social Distress and the Homeless, 2, 177-192.
Sommers, S. R., \& Norton, M. I. (2006). Lay theories about white racists: What constitutes racism (and what doesn't). Group Processes $\mathcal{E}$ Intergroup Relations, 9, 117-138.

Stevens, L. E., \& Fiske, S. T. (1995). Motivation and cognition in social life: A social survival perspective. Social Cognition, 13, 189-214.

Su, S. K., Chiu, C-y., Hong, Y., Leung, K., Peng, K., \& Morris, M. W. (1999). Self organization and social organization: American and Chinese

constructions. In T. R. Tyler, R. Kramer, \& O. John (Eds.), The psychology of the social self (pp. 193-222). Mahwah, NJ: Erlbaum.

Tong, Y., \& Chiu, C-y. (2002). Implicit theories and evaluation-based organization of impressions: An application of the memory search paradigm. Personality and Social Psychology Bulletin, 28, 1518-1527.

Weber, M. (1904-1905/1958). The Protestant ethic and the spirit of capitalism. (T. Parsons, Trans.). New York: Scribner's.

Wegener, D. T., \& Petty, R. E. (1998). The naive scientist revisited: Naive theories and social judgment. Social Cognition, 16, 1-7.

Wyer, R. S. (2004). The role of situation models, narratives and implicit theories. Mahwah, NJ: Erlbaum.

Yzerbyt, V., Corneille, O., \& Estrada, C. (2001). The interplay of subjective essentialism and entitativity in the formation of stereotypes. Personality and Social Psychology Review, 5, 141-155.

Yzerbyt, V., Judd, C. M., \& Corneille, O. (Eds.) (2004). The psychology of group perception: Perceived homogeneity, entitativity, and essentialism. New York: Psychology Press.

Yzerbyt, V., Rocher, S., \& Schadron, G. (1997). Stereotypes as explanations: A subjective essentialistic view of group perception. In R. Spears, P. J. Oakes, N. Ellemers, \& S. A. Haslam (Eds.), The social psychology of stereotyping and group life (pp. 20-50). Oxford: Basil Blackwell.

Yzerbyt, V., Rogier, A., \& Fiske, S. T. (1998). Group entitativity and social attribution: On translating situational constraints into stereotypes. Personality and Social Psychology Bulletin, 24, 1089-1103.

\section{Biographical notes}

SHERI R. LEVY is an assistant professor of psychology at the State University of New York at Stony Brook. She received her $\mathrm{PhD}$ at Columbia University in New York City. Her research interests include understanding processes that contribute to prejudice and the role of people's lay theories in intergroup relations. 
CHI YUE CHIU is a professor of psychology at the University of Illinois at Urbana-Champaign. He received his $\mathrm{PhD}$ from Columbia University in New York City in 1994, and had taught in the department of psychology of the University of Hong Kong for several years before he moved to the University of Illinois in 2002. His current research projects focus on multicultural psychology, cultural identification, group processes and intergroup relations, communication and cognition.
YING-YI HONG is a professor of psychology at the University of Illinois at Urbana-Champaign. She received her $\mathrm{PhD}$ from Columbia University in New York City. Her research interests include implicit theories and group processes, biculturalism, and self and identity. 